\title{
THE HUMAN HAIR FOLLICLE PULSATING BIOMAGNETIC FIELD REACH AS POSSIBLE ADDITIONAL FACTOR IN MIGRAINE HEADACHES A BIOPHYSICS BASED HYPOTHESIS
}

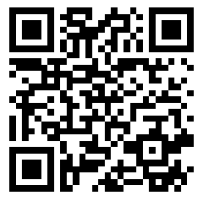

\author{
Abraham A. Embi ${ }^{*}{ }^{\circledR}$ \\ ${ }^{1}$ BS, MBA, Citizen Scientist, 13442 SW 102 Lane Miami, Florida, 33186 USA
}

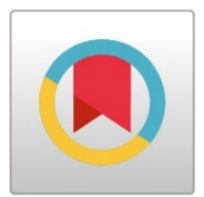

DOI: https://doi.org/10.29121/granthaalayah.v8.i5.2020.179

Article Type: Research Article

Article Citation: Abraham A. Embi. (2020). THE HUMAN HAIR

FOLLICLE PULSATING

BIOMAGNETIC FIELD REACH AS

POSSIBLE ADDITIONAL FACTOR IN

MIGRAINE HEADACHES A

BIOPHYSICS BASED HYPOTHESIS.

International Journal of Research -

GRANTHAALAYAH, 8(5), 221-229.

https://doi.org/10.29121/granthaa

layah.v8.i5.2020.179

Received Date: 19 May 2020

Accepted Date: 31 May 2020

Keywords:

Hair Magnetic Field

Biomagnetic Field Reach

Hair Follicle Biomagnetism

Follicle Pulsating Biomagnetism

Migraine Headaches

Blood and Hair Paramagnetim

\section{ABSTRACT}

This manuscript introduces a hypothesis linking the intrinsic pulsating nature of the biomagnetic fields reach found in the human hair follicle as factor in the etiology of migraine headaches. In the last two decades, researchers have emphasized the efficiency of external pulsed electromagnetic fields in the treatment of migraine headaches.

Clinical trials have also demonstrated that external pulsed electromagnetic fields may prevent or decrease the migraine attacks. A hypothesis is presented linking the inherent hair follicle pulsed bioelectomagnetism as a factor in the etiology of migraines. Does the internal pulsed biomagnetic field reach of the hair follicles factor in the genesis of migraine headaches? Supporting the hypothesis are published papers confirming the inherent biomagnetism of the human hair follicle. The introduction of a novel optical microscopy technique using a special Prussian Blue Stain (PBS) mixed with fine iron particles has produced numerous papers confirming the inherent biomagnetism of the human hair. This manuscript expands on those findings by introducing documentation of the hair follicle pulsating biomagnetic field reach. This is demonstrated by using diamagnetic as well as paramagnetic preparations mixed with iron particles. Still microphotographs and video-recordings are presented.

\section{INTRODUCTION}

Ever since the introduction of a simplified method for the detection of electromagnetic energy in plants and animal tissue [1]; the intrinsic biomagnetism of the humans and rodents hair follicles have been documented [2], [3], [4], [5]. Of relevancy to this manuscript is a published paper demonstrating the hair follicle biomagnetic fields penetrating through a $25 \times 75 \times 1 \mathrm{~mm}$ glass slide [6]. This finding triggered the idea of measuring the biomagnetic reach of the human hair follicle. The intrinsic unique pulsating nature of biomagnetic fields emitted by the hair follicle has been observed by this researcher for years; and its hypothesized clinical application has remained stored in files until recently. Prior to this manuscript, it has been hypothesized that reactive oxygen species (ROS) could be an additional factor in migraine etiology [7]. Not until recently is that the idea linking the internal pulsed magnetic fields hypothesis surfaced. it happened while revisiting my files and finding from a literature search papers documenting

(C) 2020 The Author(s). This is an open access article distributed under the terms of the Creative Commons Attribution License, which permits unrestricted use, distribution, and reproduction in any medium, provided the original author and source are credited. 
The Human Hair Follicle Pulsating Biomagnetic Field Reach as Possible Additional Factor in Migraine Headaches A Biophysics Based Hypothesis

the external pulsed effects on nerve endings [8], the initial exploration of pulsing electromagnetic fields for the treatment of headache [9]; and subsequent double blind-placebo controlled studies and others [10], [11], [12].

\section{MATERIALS AND METHODS}

Special Prussian Blue Stain solution supplied by Benjamin Scherlag PhD, Professor of Medicine, Health Science Center, Oklahoma University, Oklahoma City, USA.

Method Reproduced from reference [1]

"A fine iron particle solution was prepared by mixing several grams of powdered iron filings (Edmond Scientific, Co., Tonawanda, NY) in 200 cc of deionized water. After standing for several hours the supernatant was carefully decanted for sizing of the iron particles. The particle size and distribution of the particles from the supernatant was determined using dynamic light scattering (DLS) and the zeta potential using phase analysis light scattering by a Zeta potential analyzer (ZetaPALS, Brookhaven Instruments Corp, Holtsville, NY). For sizing, $1.5 \mathrm{ml}$ of the solution in de-ionized water was scanned at $25^{\circ} \mathrm{C}$ and the values obtained in nanometers $(\mathrm{nm})$. A similar aliquot of the fine iron particle solution was scanned for 25 runs at $25^{\circ} \mathrm{C}$. for determining zeta potentials. Zeta potential values were displayed as millivolts $(\mathrm{mV})$. Using a transfer pipette, aliquots of the solution containing the iron particles (mean particle size, 2 microns) were combined with Prussian Blue Stain (PBS Fe 2, 2.5\% potassium ferrocyanide and 2.5\% hydrochloric acid)" [1].

Potassium Ferrocyanide solution prepared as follows:

- $\quad 2.5 \%$ Potassium Ferrocyanide solution $\left(\mathrm{K}_{4} \mathrm{Fe}_{2} \mathrm{CN}_{6}\right)$ and a $2.5 \% \mathrm{HCl}$. Also added were two parts of the $\mathrm{Fe}$ 2000 solution. The composite solution is abbreviated throughout the manuscript as $\mathrm{Fe}_{2}$.

- A solution having paramagnetic properties was also prepared by using aliquots of a Potassium Ferricyanide solution as follows:

- $2.5 \%$ Potassium Ferricyanide solution $\left(\mathrm{K}_{4} \mathrm{Fe}_{3} \mathrm{CN}_{6}\right)$ and a $2.5 \% \mathrm{HCl}$, also added were two parts of the $\mathrm{Fe}$ 2000 solution. The composite solution is abbreviated throughout the manuscript as $\mathrm{Fe}_{3}$.

\subsection{THE SINGLE SLIDE PREPARATION}

To display the horizontal magnetic forces, a human hair plucked from the author's forearm was placed on a clean slide (size $25 \times 75 \times 1 \mathrm{~mm}$ ). Two drops of the Fe2 solution covered the follicle and shaft and was then allowed to evaporate unimpeded at room temperature (77 F, 48\% humidity). This preparation will be referred as a single slide preparation of (SSP).

This solution will be referred as $\mathrm{PBS} \mathrm{Fe}_{2}$ or $\mathrm{PBS} \mathrm{Fe}_{3}$ throughout the manuscript. One freshly plucked forearm human hair was sequentially used for all three experiments.

\subsection{THE SANDWICH PREPARATION (SDW)}

The hair was placed on a $25 \times 75 \times 1 \mathrm{~mm}$ glass slide, and then covered by an equally sized slide. This preparation is referred in this manuscript as a sandwich (SDW).

\subsection{THE STACKED SLIDE PREPARATIONS}

Glass slides were sequentially assembled to increase the vertical distance from the sandwiched hair follicle to the PBS Fe solutions at $1 \mathrm{~mm}$ stages (Figure 1) 

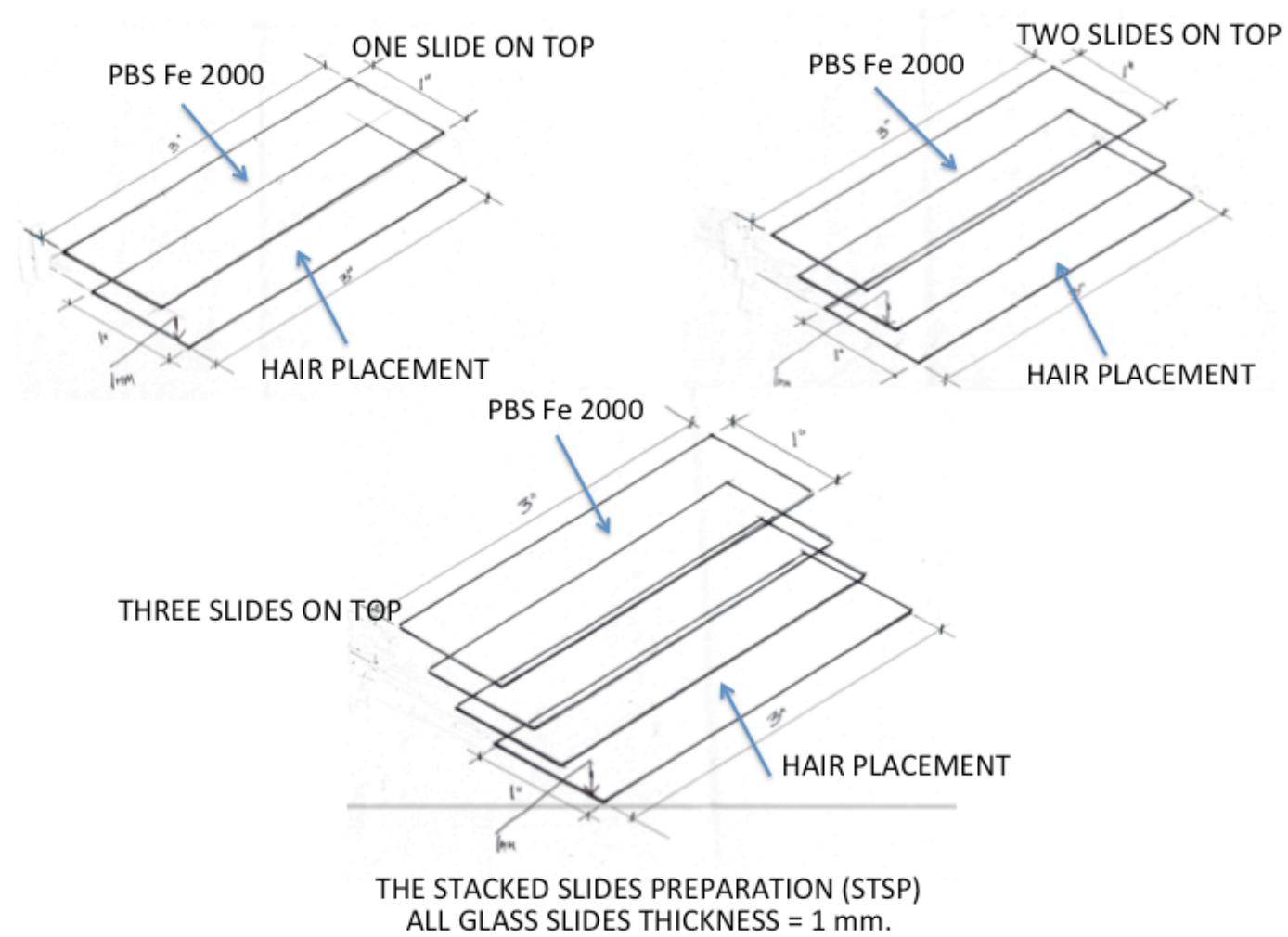

Figure 1: The stacked slide preparations. Above drawings showing the three different types of slide assemblies to measure the human hair vertical effective electromagnetic force effect on crystallization of a PBS Fe 2000 solution.

Image reproduced from: Cite This Article: Abraham A. Embi Bs. (2018). "THE HUMAN HAIR FOLLICLE PULSATING BIOMAGNETIC FIELD REACH AS MEASURED BY CRYSTALS ACCRETION." International Journal of Research - Granthaalayah, 6(7), 290-299. https://doi.org/10.5281/zenodo.1341349.

\subsection{HAIR IN SDW AT 1 MM VERTICAL DISTANCE FROM PBS FE2 DROPS}

A hair was placed on a single clean slide (size $25 \times 75 \times 1 \mathrm{~mm}$ ), this time a second slide was placed on top. On the top slide two drops of PBS Fe were placed and allowed to evaporate. The PBS Fe2 fluid is now at a vertical distance by $1 \mathrm{~mm}$. Two drops of the PBS Fe2 solution were then applied to the top slide (covering the hair follicle out of focus outline and allowed to evaporate.

\subsection{HAIR IN SDW AT 2 MM VERTICAL DISTANCE FROM THE PBS FE2 DROPS}

The same technique as above was duplicated, except that this time the SDW had two glass slides on the top surface. This made the hair follicle to PBS Fe2 solution at $2 \mathrm{~mm}$.

\subsection{HAIR IN SDW AT 3 MM VERTICAL DISTANCE FROM THE PBS FE2 DROPS}

The same technique was reproduced, except that this time the SDW had three slides on the top surface. This made the hair follicle to PBS Fe solution distance at $3 \mathrm{~mm}$.

Note: In all three slides preparations the PBS Fe2 was allowed to evaporate. Still images and video-recordings were made by using a Celestron II video-microscope. The images downloaded onto an Apple computer MacBook Pro Photo Application. 
The Human Hair Follicle Pulsating Biomagnetic Field Reach as Possible Additional Factor in Migraine Headaches A Biophysics Based Hypothesis

\section{RESULTS}

\subsection{THE HAIR VERTICAL BIOMAGNETIC FIELD RANGE.}

\subsubsection{ONE SLIDE COVERING THE HAIR (VIDEO-RECORDING ANALYSIS)}

As previously described, a freshly plucked forearm hair follicle was placed onto the center of a clean slide. The sticky property of a fresh follicle made it easy for adherence to the glass slide, care was taken to maneuver the shaft with a toothpick, and assure that it was also within the slide's boundaries.

Another clean slide was then placed on top of the first and two drops of the PBS Fe2 solution was applied. The thickness of the glass slide measures $1 \mathrm{~mm}$, therefore no physical contact with the hair below. The solution was allowed to evaporate and continuously monitored. As the evaporation line reached the latitude in front of the root, it stopped and then continues its path (Fig 2) and supplementary video:

https://youtu.be/uddsCIeEdMc

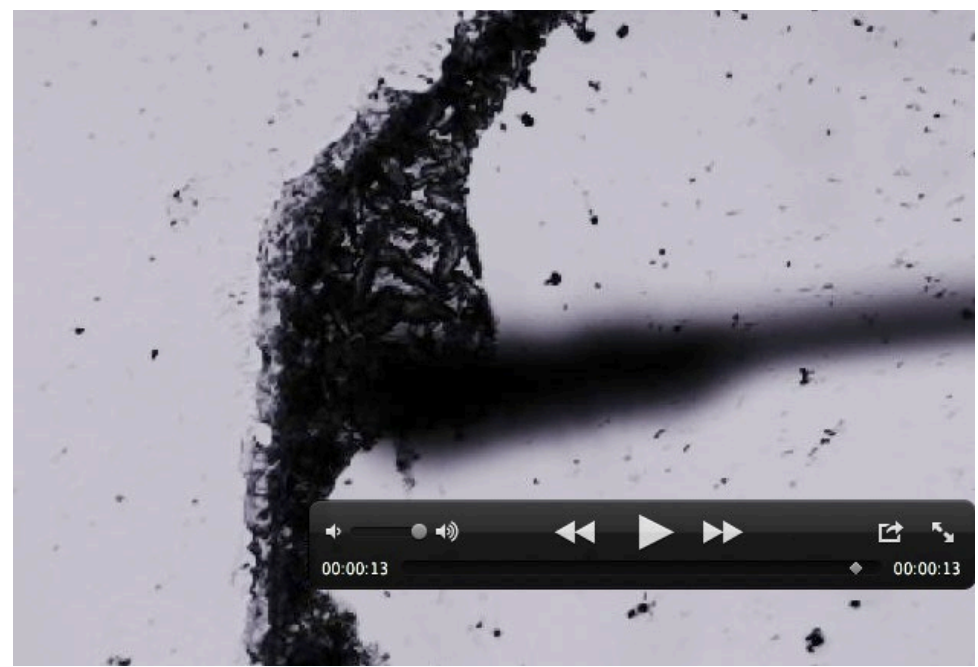

Figure 2: One vertically stacked slide. The hair was placed on a clean slide. Another slide covered the hair and three drops of the PBS Fe solution was allowed to evaporate. This photograph of a Video frame shows the crystallization line stopped by the biomagnetic field reach of the hair follicle. Total vertical distance from hair to top surface = $1 \mathrm{~mm}$. Please visit linlk \#0592 AVI for further details: https://youtu.be/uddsCIeEdMc

Reproduced from: Cite This Article: Abraham A. Embi Bs. (2018). “THE HUMAN HAIR FOLLICLE PULSATING BIOMAGNETIC FIELD REACH AS MEASURED BY CRYSTALS ACCRETION.” International Journal of Research Granthaalayah, 6(7), 290-299. https://doi.org/10.5281/zenodo.1341349.

Large crystals were formed and fixed in place forming a structured evaporation line. Notably, this time the crystallization line also had a curved appearance. Is theorized that this was as result of the vertical biomagnetic field reach as shown by the crystals deposition emitted by the hair trapped in the bottom slide was $1 \mathrm{~mm}$

\subsection{TWO SLIDES COVERING THE HAIR SDW}

The top slide was removed; care was taken to assert that the hair on the bottom slide remained in position. This time two additional $1 \mathrm{~mm}$ slides were added to the SDW. Two drops of the PBS Fe2 solution were also applied. The top slide was allowed to evaporate, this time also the evaporation line stopped in front of the root area for approximately the same time and then continue its path past the bulb and permanently stopped over the bulge area (Figure 3). 


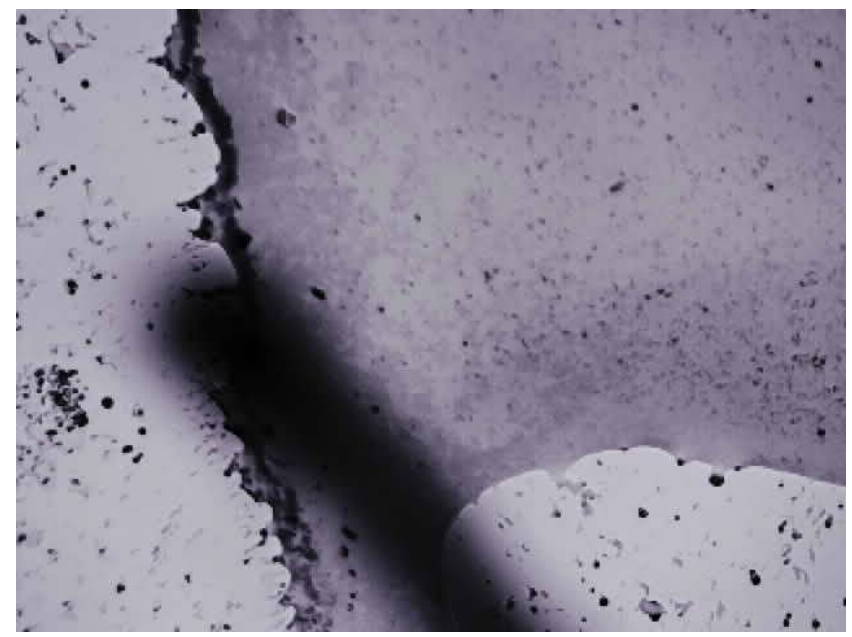

Figure 3: Two vertically staked slide. The hair was placed on a clean slide. Two clean slides covered the hair and three drops of the PBS Fe 000 solution was placed on the uppermost slide and allowed to evaporate. This photograph of a Video frame shows the crystallization line stopped by the biomagnetic field reach of the hair follicle. Since now we have two slides covering the hair, the crystallization line width is less pronounced and shifted to the right of the bulb.Total distance from hair to top slide $2 \mathrm{~mm}$.

Reproduced from: Cite This Article: Abraham A. Embi Bs. (2018). "THE HUMAN HAIR FOLLICLE PULSATING BIOMAGNETIC FIELD REACH AS MEASURED BY CRYSTALS ACCRETION." International Journal of Research Granthaalayah, 6(7), 290-299. https://doi.org/10.5281/zenodo.1341349.

This time the evaporation showed a latitudinal shift. Now instead of stopping over the bulb area, it was seen over the bulge area. This is attributed to the "Faraday Effect" on EMF vertical propagation. The distance now for the vertical effective magnetic force effect on crystallization was $2 \mathrm{~mm}$. Please note that the thickness of the crystallization line is inversely proportional to the Biomagnetical Field Reach distance

\subsection{THREE SLIDES COVERING HAIR}

This time the top slide was removed and two clean slides were added; thus making the hair follicle to the top slide at a vertical distance of $3 \mathrm{~mm}$. The evaporation line was unaffected and continued in its path. The distance now from the hair to the top slide surface was $3 \mathrm{~mm}$.

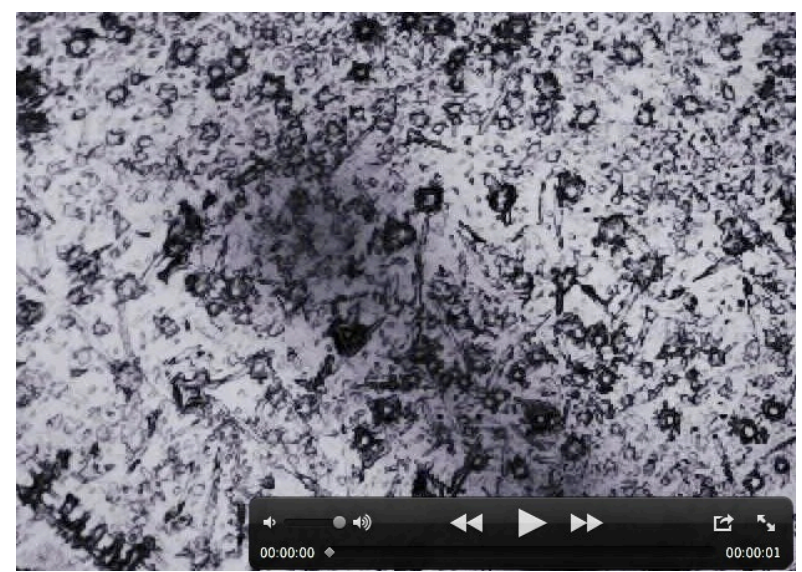

Figure 4: Three slides on top of hair. The hair was placed on a clean slide and seen out of focus in the background. Three clean slides covered the hair and three drops of the PBS Fe 2000 solution was placed on the uppermost slide and allowed to evaporate. This photograph of a video frame shows the absence of a crystallization pattern. The random occurrence of crystals is a demonstration that the biomagnetic field reach range of the human hair magnetism is ineffective at a distance of $3 \mathrm{~mm}$ from the source (hair). 
Image reproduced from: Cite This Article: Abraham A. Embi Bs. (2018). "THE HUMAN HAIR FOLLICLE PULSATING BIOMAGNETIC FIELD REACH AS MEASURED BY CRYSTALS ACCRETION." International Journal of Research - Granthaalayah, 6(7), 290-299. https://doi.org/10.5281/zenodo.1341349.

\section{Additional Supplementary Images.}

The author recommends viewing supplementary video recordings and Figure 5 (below) for further details:

- For Figure 2 https://youtu.be/uddsCIeEdMc

- For Figure 7 https://youtu.be/6iKcEvxY_zE

- For Figure 8 https://youtu.be/8pipWJVytrk.

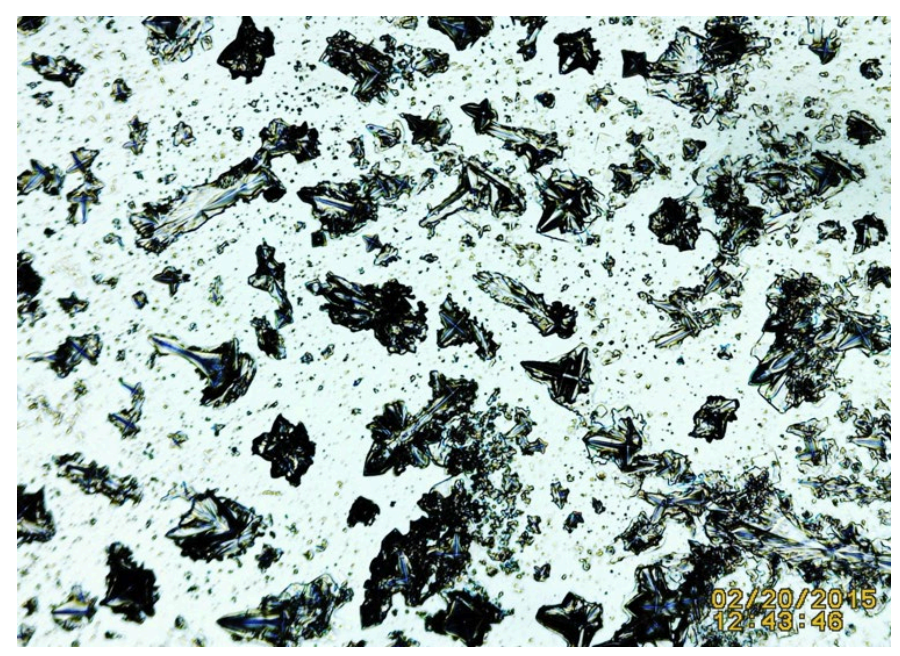

Figure 5: Example of control unimpeded evaporation of a SSP with PBS Fe 2000 solution. Notice the homogeneous appearance (no line clumping) in the crystals distribution in the absence of a biomagnetic field reach.

Image reproduced from: Cite This Article: Abraham A. Embi Bs. (2018). "THE HUMAN HAIR FOLLICLE PULSATING BIOMAGNETIC FIELD REACH AS MEASURED BY CRYSTALS ACCRETION.” International Journal of Research - Granthaalayah, 6(7), 290-299. https://doi.org/10.5281/zenodo.1341349.

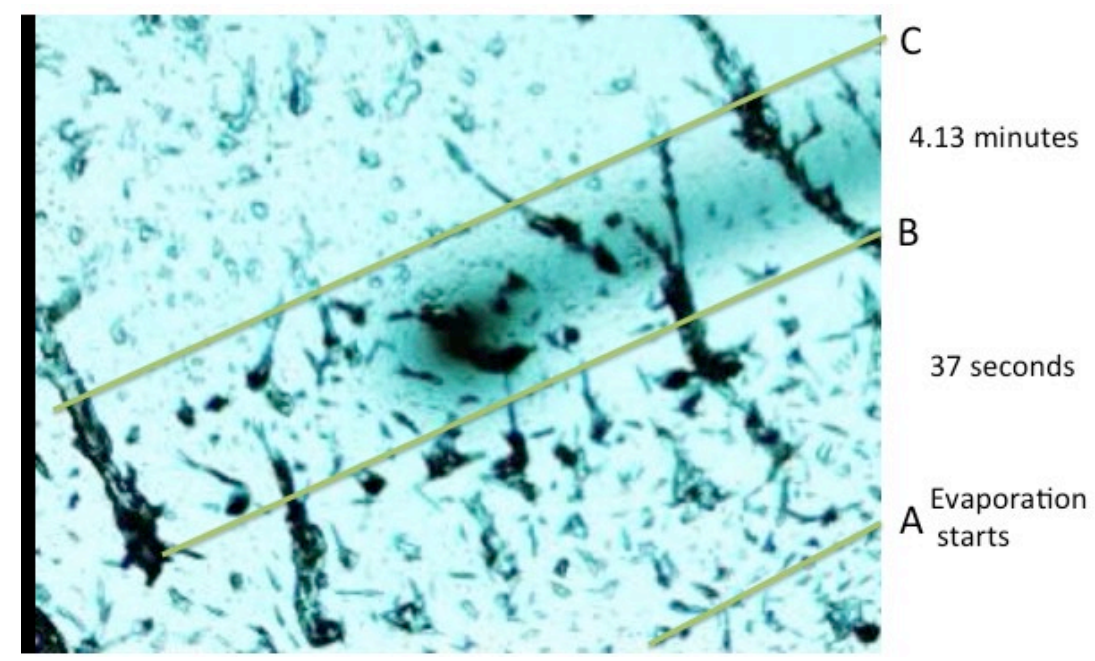

Figure 7: $\mathrm{n}=2$ experiment. Hair Follicle in SDW at $1 \mathrm{~mm}$ vertical distance from the PBS Fe evaporated crystals. The video-recording shows timing of the evaporation process as follows: From $A$ to $B=31$ seconds From $B$ to $C=$ 4.13 minutes. There is a noticeable delay in the crystallization advance as the evaporation line is influenced by the

https://youtu.be/6iKcEvxY_z biomagnetic field reach of the hair follicle. Please visit video link for details: 
Image reproduced from:

Cite This Article: Abraham A. Embi Bs. (2018). "THE HUMAN HAIR FOLLICLE PULSATING BIOMAGNETIC FIELD REACH AS MEASURED BY CRYSTALS ACCRETION.” International Journal of Research - Granthaalayah, 6(7), 290299. https://doi.org/10.5281/zenodo.1341349.

\section{RESULTS}

\subsection{BIOMAGNETIC FIELD REACH OF THE HAIR FOLLICLE USING A DIAMAGNETIC SOLUTION AS SENTINEL}

Using a tabletop optical microscopy technique; and a Prussian Blue solution tailored to detect biomagnetic fields in plants and animal tissues, the human hair biomagnetical field reach distance was measured. A fresh tweezers plucked in toto (root and shaft) hair was sandwiched (SDW) between two $1 \mathrm{~mm}$ thick glass slides. The PBS Fe2 solution was placed on the top slide and allowed to evaporate. Video-recordings of the event were recorded and analyzed. The same procedure was done by preserving the original hair in the SDW and increasing the hair to PBS distance by $1 \mathrm{~mm}$ increments.

All recordings showed an effect on the crystallization advance by the biomagnetic field reach of the hair. The effect was not detected at a maximum vertical distance of $3 \mathrm{~mm}$. After analyzing the data, it was concluded that the vertical hair follicle biomagnetic reach using a diamagnetic solution is $\geq 2 \leq 3 \mathrm{~mm}$.

\subsection{BIOMAGNETIC FIELD REACHOUT OF THE HAIR FOLLICLE USING A PARAMAGNETIC SOLUTION AS SENTINEL}

The same procedures were conducted, this time using PBS mixed with Potassium Ferricyanide (paramagnetic solution), The results were slightly different, the hair follicle biomagnetic field reachout was detected at $3 \mathrm{~mm}$ vertical distance (Fig 8).
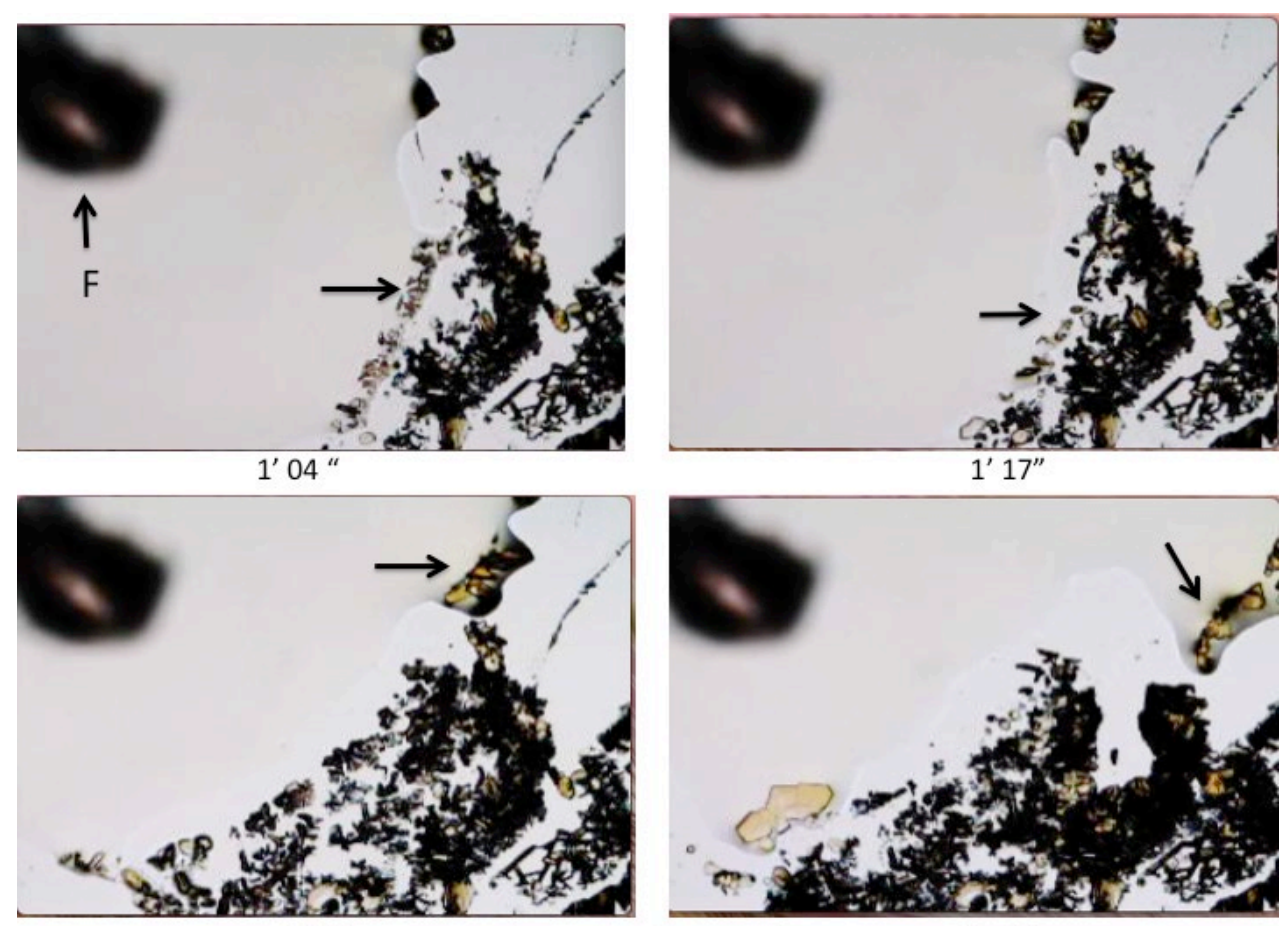

$2^{\prime} 17$

$'=$ minutes "= seconds

3' 49"

Figure 8: Panel showing time lapse still frames from video-recording of effect of F= Hair Follicle biomagnetism. Hair (out of focus) mounted in glass slide and vertically separated by a similar $1 \mathrm{~mm}$ slide. The top slide has drops of Prussian Blue Stain + iron sized nanoparticles; the sequence shows energy from follicle rejecting the crystallization advance (black arrows) of a Ferricyanide (paramagnetic solution).

Please, refer to complimentary video: https://youtu.be/8pipWJVytrk . 
The Human Hair Follicle Pulsating Biomagnetic Field Reach as Possible Additional Factor in Migraine Headaches A Biophysics Based Hypothesis

Image reproduced from: Cite This Article: Abraham A. Embi Bs. (2018). "THE HUMAN HAIR FOLLICLE PULSATING BIOMAGNETIC FIELD REACH AS MEASURED BY CRYSTALS ACCRETION." International Journal of Research - Granthaalayah, 6(7), 290-299. https://doi.org/10.5281/zenodo.1341349.

The video in Figure 8 clearly depicts the pulsating property of the bioelectromagnetic fields reach fluctuating forces of the hair follicle penetrating a $1 \mathrm{~mm}$ glass barrier and repelling the advance of a paramagnetic solution.

\section{CONCLUSIONS}

The hair follicle has been described as a dynamic mini-organ with a variety of different cells interactions and fluctuating metabolic processes (13). Due to the hair follicle intrinsic electron transport-based metabolism these biologic entities emit variables or "pulsating" electromagnetic fields.

The experiments demonstrate (when using the slide technique) that the human hair follicle biomagnetic fields reach measure $\geq 2 \leq 3 \mathrm{~mm}$ when detecting a diamagnetic (repulsing a magnetic field) solution. When a paramagnetic solution (attracted to a magnetic field) is used the hair follicle vertical biomagnetic field reach out was approximated at $3 \mathrm{~mm}$. Both solutions caused delays in the evaporation line.

\subsection{PULSATING BIOMAGNETISM TOWARDS PARAMAGNETIC SUBSTANCE}

Visually, it appears to be greater fluctuations in the evaporation linear movement when a paramagnetic substance is used. Demonstrated is the human hair pulsed biomagnetic field reach when using two magnetically divergent solutions. As a note of interest, the human blood tissue is known to be paramagnetic (14).

\subsection{THE HYPOTHESIS}

The above-described findings support a hypothesis stating that:

"The intrinsic pulsating biolectromagnetic field reach of the hair follicle may be a factor triggering migraine headaches". The mechanism theorized to involve both human blood and hair follicles biophysical interactions, possibly affecting scalp nerve endings.

\section{SOURCES OF FUNDING}

None.

\section{CONFLICT OF INTEREST}

None.

\section{ACKNOWLEDGMENT}

None.

\section{REFERENCES}

[1] Benjamin J. Scherlag, Kaustuv Sahoo, Abraham A. Embi A. Novel and Simplified Method for Imaging the Electromagnetic Energy in Plant and Animal Tissues. Journal of Nanoscience and Nanoengineering Vol. 2, No. 1, 2016, pp. 6-9.

[2] Embi AA, Jacobson JI, Sahoo K, Scherlag BJ (2015) Demonstration of Inherent Electromagnetic Energy Emanating from Isolated Human Hairs. Journal of Nature and Science, 1(3): e55. 
[3] Embi AA, Scherlag BJ. Human Hair Follicle Biomagnetism: Potential Biochemical Correlates. J Mol Biochem. $2015 ; 4: 32-35$.

[4] Embi AA, Jacobson JI, Sahoo K, Scherlag BJ (2015) Demonstration of Electromagnetic Energy Emanating from Isolated Rodent Whiskers and the Response to Intermittent Vibrations. Journal of Nature and Science, 1(3): e52.

[5] Scherlag BJ, Huang B, Zhang l, Sahoo K, Towner R, Smith N, Embi AA, Po SS (2015) Imaging the Electromagnetic Field of Plants (Vigna radiata) Using Iron Particles: Qualitative and quantitative correlates. Journal of nature and Science 1(3): e61.

[6] Abraham A. Embi, Benjamin J. Scherlag. Demonstration of Human Hair Follicle Biomagnetic Penetration Through Glass Barriers. International Journal of Materials Chemistry and Physics Vol. 2, No. 2, 2016, pp. 7174

[7] Embi AA. Topical In Vivo Liquid Catalase on Scalp and Migraine Headache Cessation in an Adolescent: A Biophysics Based Hypothesis. J Nat Sci, 2017 3(3): e330.

[8] Mert T, Gunay I, Gocmen C, Kaya M, Polat S. Regenerative effects of pulsed magnetic field on injured peripheral nerves. Altern Ther Health Med. 2006 Sep-Oct;12(5):42-9.

[9] Sherman RA, Robson L, Marden LA. Initial exploration of pulsing electromagnetic fields for treatment of migraine. Headache. 1998 Mar;38(3):208-13. PMID:9563212

[10] Sherman RA, Acosta NM, Robson L. Treatment of migraine with pulsing electromagnetic fields: a doubleblind, placebo-controlled study. Headache. 1999 Sep;39(8):567-75. PMID:11279973

[11] Boshra Hatef, Fahime Hashemirad, Gholam Hossein Meftahi, Leila Simorgh, Soodeh Razeghi Jahromi, Forough Rahimi, Mansoureh Togha. The efficiency of pulsed electromagnetic field in refractory migraine headaches: a randomized, single-blinded, placebo-controlled, parallel group. International journal of clinical trial 3(1): 2431,2016

[12] B Hatef, B Majdoleslam, M Toghae, F Hashemirad. The Prophylactic Treatment of PEMF in the Refractory Migraine Headache, Double-Blind, Parallel Placebo-Controlled Study. CEPHALALGIA 33(s8): 98-99, 2013

[13] Schneider MR, Schmidt-Ullrich R, Paus R. The hair follicle as a dynamic miniorgan. Curr Biol. 2009 Feb 10;19(3): R132-42. doi: 10.1016/j.cub.2008.12.0

[14] Kara L. Bren, Richard Eisenberg, Harry B. Gray. Discovery of the magnetic behavior of hemoglobin (2015) Proceedings of the National Academy of Sciences Oct 2015, 112 (43) 1312313127; DOI:10.1073/pnas.1515704112. 